\title{
Preserved Spatial Coding in Hippocampal CA1 Pyramidal Cells During Reversible Suppression of CA3c Output: Evidence for Pattern Completion in Hippocampus
}

\author{
S. J. Y. Mizumori, B. L. McNaughton, C. A. Barnes, and K. B. Fox \\ Department of Psychology, University of Colorado, Boulder, Colorado 80309
}

\begin{abstract}
Medial septal modulation of hippocampal single-unit activity was examined by assessing the behavioral and physiological consequences of reversibly inactivating the medial septum via microinjection of a local anesthetic (tetracaine) in freely behaving rats trained to solve a working memory problem on a radial maze. Reversible septal inactivation resulted in a dramatic, but temporary (15-20 min), impairment in choice accuracy. In addition, movement-induced theta $(\theta)$ modulation of the hippocampal EEG was eliminated. Septal injection of tetracaine also produced a significant reduction in location-specific firing by hilar/CA3c complex-spike cells (about $50 \%$ ), with no significant change in the place-specific firing properties of CA1 complex-spike units. The mean spontaneous rates of stratum granulosum and $\mathrm{CA} 1$ theta cells were temporarily reduced by about $50 \%$ following septal injection of tetracaine.

Although there was a significant reduction in the activities of inhibitory interneurons (theta cells) in CA1, there was no loss of spatial selectivity in the CA1 pyramidal cell discharge patterns. We interpret these results as support for the proposal originally put forth by Marr $(1969,1971)$ that hippocampal circuits perform pattern completion on fragmentary input information as a result of a normalization operation carried out by inhibitory interneurons. A second major finding in this study was that location specific firing of CA1 cells can be maintained in the virtual absence of the hippocampal $\theta$-rhythm.
\end{abstract}

In a previous study (Mizumori et al., 1989a), we demonstrated in anesthetized animals that local inactivation of medial septum (probably including fibers coursing through it) resulted in a substantial reduction in the mean spontaneous firing rates in $\mathrm{CA} 3 \mathrm{c}$ pyramidal cells. Somewhat surprisingly there was no significant effect in the spontaneous activity of pyramidal cells recorded in CA1. These data raised the possibility that output of CA1 pyramidal cells was determined by a balance between feedforward excitation and feedforward inhibition that results from direct connections between Schaffer collaterals and inhibitory inter-

\footnotetext{
Received Jan. 12, 1989; revised Apr. 6, 1989; accepted May 3, 1989.

We express appreciation to Kelly Grewell, Iris Lutz, and Carol Maurer for assistance with the behavioral training of the animals. We also thank Shelly ScottNash for computer assistance and Carol Elkins for assistance with the histological preparations. This research was supported by National Institutes of Health grants to S. J. Y. M. (AG05375), to C. A. B. (AG00376), and to B. L. M. (NS20331).

Correspondence should be addressed to Dr. Sheri J. Y. Mizumori at the above address.
}

Copyright (c) 1989 Society for Neuroscience $0270-6474 / 89 / 113915-14 \$ 02.00 / 0$ neurons. We conjectured that this effect was consistent with the property of associative recall, or "pattern completion" originally postulated by Marr $(1969,1971)$ and more recently elaborated by McNaughton and Morris (1987) and McNaughton and Nadel (1989). The prediction of this hypothesis is that, in freely moving animals, a reduction of CA $3 \mathrm{c}$ output should leave not only the spontaneous rates of CA1 intact but also the well-known spatial selectivity of CAl discharge (O'Keefe and Dostrovsky, 1971; O'Keefe, 1976; McNaughton et al., 1983a; Muller et al., 1987). A further goal of the present study was to assess the contribution of the rhythmic modulation of the hippocampal EEG, i.e., the theta $(\theta)$ rhythm, to spatially selective discharge.

A majority of medial septal afferents to the hippocampus synapse on cells located in facia dentata and the CA $3 \mathrm{c}$ subfield (Swanson and Cowan, 1979). Since many of the septal terminals are located on inhibitory interneurons (Freund and Antal, 1988), it would be expected that the septum exerts a significant modulatory influence on the activity of granule and pyramidal cells. Indeed, electrical prestimulation of the medial septum appears to increase the excitability of the granule cell population by attenuating feedforward inhibition in stratum granulosum (e.g., Alvarez-Leefmans and Gardner-Medwin, 1975; Fantie and Goddard, 1982; Bilkey and Goddard, 1985, 1987; Mizumori et al., 1989b). Furthermore, it is clear that behaviors that are disrupted by hippocampal lesions are also severely affected by a lesion of septal cells or their fibers (e.g., DeCastro, 1974; Olton et al., 1978b; Becker et al., 1980; Crutcher et al., 1981). However, the influence of the septum on the behavioral correlates of hippocampal single-unit activity is presently not well understood.

Medial septal modulation of hippocampal single-unit responses to sensory stimuli was initially studied in conscious, immobilized animals. Miller and Groves (1977) showed that a majority of hippocampal cells recorded from curarized rats responded to sensory stimulation by reducing their rate of spontaneous discharge. Medial septal lesions abolished spontaneous firing of many hippocampal cells and reduced the inhibitory responses to sensory stimuli. Vinogradova and Brazhnik (1978) recorded hippocampal unit activity in response to presentation of a variety of sensory stimuli in restrained rabbits. In contrast to the findings of Miller and Groves, it was found that following septal lesions CA1 cells continued to respond to sensory stimuli in the same manner as before the lesion, while the response of CA3 units was greatly reduced.

The effects of septohippocampal disconnection on spontaneous discharge characteristics of hippocampal cells have also been examined in freely moving animals. Miller and Best (1980) 
reported that fornix lesions slightly reduced the number of CA1 complex-spike cells that exhibited the sort of location-specific firing patterns described by O'Keefe (1976) and O'Keefe and Dostrovsky (1971). Furthermore, and in contrast to cells from control rats, CAl place cells from lesioned rats were more susceptible to disruption following maze rotation. At variance with the findings of Miller and Best, Buzsaki et al. (1983) concluded that complex-spike cells are relatively unaffected by medial septal lesions in chronically prepared rats (although it was not reported whether these cells were recorded in CA1 or CA3).

Buzsaki et al. (1983) also examined the effects of septal lesions on putative granule cell and interneuron firing rates in stratum granulosum. They found that cells recorded after a lesion fired at a higher rate than different cells recorded before the lesion. The stratum granulosum units continued to increase their activity during voluntary movement, although the firing pattern was no longer rhythmic. Rose (1983) also found that the activity of putative granule cells recorded from septal-lesioned rats varied according to movements made by the animal. However, it was shown that these cells were less sensitive to the precise moment of initiation and termination of behaviors. Consistent with Rose's result, Foster et al. (1988) reported that putative granule cells of septal-lesioned rats were less responsive to changes in the sensory environment. In contrast to the results of Buzsaki et al., however, Foster et al. found no change in the spontaneous firing rate of presumed granule cells. Finally, Bland and Bland (1986) reported that the firing rate of CAl and dentate "theta" cells of freely moving rabbits was reduced by about $50 \%$ within $4 \mathrm{hr}$ of an electrolytic medial septal lesion.

The results described above do not provide a consistent account of hippocampal unit responses to septal lesion. The variability is likely due to several factors. For example, since relatively long periods of time were allowed for recovery from surgery, the results of studies involving freely moving rats were likely influenced by synaptic reorganization or retrograde degeneration. Also, while experiments with immobilized animals often tested the same cells before and after the lesion, most studies involving freely behaving animals compared the pre- and postlesion firing rates of different cells and did not take into account the possible contribution of changes in behavioral state. Furthermore, the classification of most stratum granulosum units as granule cells is questionable in light of recent evidence that the cell type most frequently encountered in stratum granulosum exhibits electrophysiological characteristics expected of inhibitory interneurons (Mizumori et al., 1989b). Moreover, since the earlier experiments recorded unit activity with single-wire electrodes, it is possible that less than optimal unit isolation compromised the interpretability of some of the results. Indeed, as emphasized by Bland (1986), some studies assessed lesion effects on multiunit activity rather than single-unit activity.

The present study demonstrates the use of a procedure that not only circumvented many of the major confounds of past lesion studies, but also allowed us to test directly the hypothesis put forth above. This procedure involves the selective and reversible inactivation of fibers originating in or traversing the medial septum by microinjection of a local anesthetic. While this approach has been used to inactivate temporarily hippocampus proper (Flicker and Geyer, 1982; Smith et al., 1983; Barea et al., 1988), afferent influences on target unit activity have been studied only in regard to other brain systems (e.g., Schiller et al., 1979; Rigdon and Pirch, 1984). In the present study, we combined the use of a modified version of an afferent inactivation technique (as described by Malpeli and Schiller, 1979 , and Schiller et al., 1979) with the stereotrode recording procedure (McNaughton et al., 1983b) to study the discharge patterns of individual hippocampal cells before, during, and after septal inactivation in freely moving animals. Since many cells of different types could be tested in the same animal performing a single task, it was possible to compare the responses of different populations of hippocampal cells. Septal inactivation effects on the hippocampal $\theta$ rhythm (Vanderwolf, 1969) were also monitored simultaneously with behavior and singleunit activity during different phases of the experiment. A preliminary report of portions of this study has been presented in abstract form (Mizumori et al., 1987).

\section{Materials and Methods}

Animals. Six male Fischer-344 rats (9-month-old retired breeders) were obtained from Charles River Laboratories. Following 1 week of adaptation to the laboratory, the rats were weighed and handled daily for 7 d. Access to food was then restricted, and, for the remainder of the experiment, rats were maintained at about $80 \%$ of their ad libitum body weights. Water was readily available. Behavioral testing occurred between 0600 and $1200 \mathrm{hr}$. Lights were on in the colony room from 0600 to $1800 \mathrm{hr}$.

Behavioral testing apparatus. A semiautomated black Plexiglas 8-arm radial maze (Olton and Samuelson, 1976) was used to test the behavioral performance of the rats. Eight alleys, or arms $(58 \times 5.5 \mathrm{~cm})$, radiated from a round central platform $(19.5 \mathrm{~cm}$ diameter) that was elevated 79 $\mathrm{cm}$ above the floor. The arms were bordered by edges raised $4 \mathrm{~mm}$ above the surface. Aluminum food cups were located at the distal ends of the arms. Each arm was hinged such that the proximal half could either be raised so that it was flush with the central platform or lowered to restrict access to that arm from the center. Presentation of individual arms was accomplished by remote control. The $12 \times 12 \mathrm{ft}$ room was illuminated by a $40 \mathrm{~W}$ white light that was locatcd on the south wall of the room. Other objects in the room that could serve as distal spatial cues included a ladder, a table, a vacuum cleaner, miscellaneous laboratory equipment, and the experimenter.

Behavior testing procedure. After the first week of food restriction, the rats were placed on the central platform of the maze with immediate access to all 8 arms. Chocolate milk reward $(0.2 \mathrm{ml})$ was placed in the food cups located at the ends of the arms. The optimal strategy for solving the maze was to enter each arm only once per trial. Reentries into previously visited arms were considered errors. During this phase of training, each rat performed one trial a day.

The initial phase of training was complete when a rat entered each arm at least once within a $20 \mathrm{~min}$ period. The second phase involved first placing the rat in the maze center without access to any arms. After 2 min, a random sample of 4 arms was simultaneously presented. When the food was retrieved from these arms, the rat was confined to the center for $1 \mathrm{~min}$ by lowering all arms. Following the delay period, all 8 arms were presented and the rat was allowed to complete the trial by selecting those arms not entered before the delay. After the rat selected the last correct arm of each trial, chocolate milk was placed on the central platform to encourage the rat to return there promptly. After 5 consecutive days of asymptotic performance, the rats were trained to perform 10 such trials a day. During this last phase of training, no delays were imposed within trials and 2 min intervened between trials. Since access to the arms was controlled by a remote switch, it was not necessary to handle the rat once a training session began. When rats performed all trials within $1 \mathrm{hr}$ for 3 consecutive days, free access to food was allowed during the next 1-2 d. Electrodes and a guide cannula were then surgically implanted (see below).

Following surgery, the rats were allowed free access to food for $7 \mathrm{~d}$. After this time, their body weights were maintained at $80 \%$ of their postsurgery ad libitum body weights. Postsurgery training was identical to the last phase of presurgery training except that the rats were required to perform 15 trials/d.

Electrode construction and surgical procedure. After the rats achieved criterion performance levels on the radial maze, a guide cannula assembly and electrodes were surgically implanted. Rats were injected (i.p.) with $33 \mathrm{mg} / \mathrm{kg} \mathrm{Nembutal}(50 \mathrm{mg} / \mathrm{ml})$. Supplements of $0.05 \mathrm{ml}$ were administered as necessary. The medial septal guide cannula assembly 
consistcd of a 25 gauge stainless steel cannula (with a 33 gauge stylet) that was inserted through a hole drilled in the center of a \#4-40 (1/8) nylon set screw and then glued in place. The set screw rested on the skull surface, thus providing a means by which the cannula could be anchored to the skull. The cannula tip was placed about $1.0 \mathrm{~mm}$ dorsal to the medial septum, according to the stereotaxic coordinates of Paxinos and Watson (1982; see Fig. 1): A-P $0.7 \mathrm{~mm}$ anterior to bregma, L. $0.0 \mathrm{~mm}, \mathrm{D}-\mathrm{V}-4.5 \mathrm{~mm}$ from the brain surface.

At surgery, bilateral recording electrodes (stereotrodes) were inserted $1 \mathrm{~mm}$ into cortex (A-P $-4.0 \mathrm{~mm}, \mathrm{~L} 2.5 \mathrm{~mm}$ ). Each stereotrode consisted of 2 lacquer-coated tungsten wires $(20 \mu \mathrm{m}$ diameter; California Fine Wire Co.) that were twisted together, dipped in Epoxylite, and then baked. The tips were cut at a $45^{\circ}$ angle, then gold-plated to give final impedances of $150-250 \mathrm{k} \Omega$ (tested at $1 \mathrm{kHz}$ ). Individual stereotrodes were threaded through a 30 gauge stainless steel tube such that $1 \mathrm{~mm}$ protruded from the end. The 30 gauge tube was mounted on a movable microdrive. A reference electrode $(114 \mu \mathrm{m}$ diameter Teflon-coated stainless steel wire) was placed into corpus callosum (A-P $-6.5 \mathrm{~mm}, \mathrm{~L}$ $2.0 \mathrm{~mm}$ ). A ground lead was soldered to a small jeweler's screw that was secured to the skull. Dental acrylic was applied to the base of the cannula assembly, microdrives, reference electrode, and ground lead. The acrylic was anchored to the skull with 4 additional stainless steel screws. Amphenol pins were attached to each electrode, reference, and ground lead, then inserted into a connecting socket (Molino and McIntyre, 1972) that was permanently attached to the animal's head, and that was later to be connected to a headstage for recording. Following surgery, the eyes were washed with ophthalamic solution and Bicillin $(0.1 \mathrm{ml})$ was administered intramuscularly to each hindleg.

In a previous experiment, we found that a majority of units recorded in stratum granulosum could reasonably be classified as inhibitory interneurons based on a number of physiological criteria, such as whether the cell was activated below population spike threshold following stimulation of perforant path and whether the same stimulus could drive the cell during population spike inhibition in paired pulse experiments (Mizumori et al., 1989a, b). Cells thus classified also had much higher mean rates than putative granule cells which failed these tests. Therefore, in order to discriminate stratum granulosum cell types in the present experiment, 2 of the rats were also implanted with Teflon-coated, stainless steel perforant path stimulating electrodes $(114 \mu \mathrm{m}$ diameter; A-P $-8.1 \mathrm{~mm}$; L $4.4 \mathrm{~mm}$ ). About $200 \mu \mathrm{m}$ of insulation was stripped from the electrode tip. Stimulus return leads were soldered to jeweler's screws that were fastened to the skull.

Behavior monitoring. Beginning 1 week after surgery, a headstage comprised of 5 FET preamplifiers and an infrared light-emitting diode was attached to the connecting socket on the rat's head during the behavioral and recording sessions. The rat's movements about the maze were monitored via an automatic tracking system which sampled and recorded the $X$-Y coordinates of the diode at a frequency of $20 \mathrm{~Hz}$ and a spatial resolution of about $1.8 \mathrm{~cm}$. The time of each position event was also logged.

Single-unit and EEG monitoring. The stereotrode recording technique was used to monitor single-unit activity (McNaughton et al., 1983b). This procedure involves independently recording cellular activity through 2 adjacent fine electrode wires. The incoming signals were amplified (5-10 K) and then filtered (at half-amplitude) at $600-800 \mathrm{~Hz}$ (high pass) and $6 \mathrm{kHz}$ (low pass). The analog signals were passed through a window discriminator such that a sampling period began when a signal from either channel exceeded a predetermined threshold. During the 1 msec sampling period, the maximum and minimum voltages of the analog signal, and the latencies of these values from the onset of the sampling period, were calculated in hardware (FMZ Electronics Co.) for each of the 2 recording channels. A PDP-11/23 computer collected these 8 spike parameters and logged the time of each event. The stereotrode recording procedure facilitates confident unit isolation by making use of the spike amplitude ratio on the 2 recording channels.

The signal from one stereotrode wire was also passed through a separate circuit in which it was amplified 30 times, then filtered at 0.5 (high pass) and $30 \mathrm{~Hz}$ (low pass) for EEG recording. This allowed us to monitor EEG simultaneously with single-unit activity. A 5.12 sec EEG sampling period was initiated each time the rat moved inward on a maze arm. EEG signals were sampled at a frcquency of $100 \mathrm{~Hz}$ and subsequently subjected to Fourier analysis.

Unit identification and analysis. Cells recorded in different hippocampal regions were identified according to the depth of the electrode, whether the cell discharged single spikes or bursts of multiple spikes, and spike duration (measured as the time difference between the maximum and minimum voltages of the analog signal). Stratum granulosum cells were encountered before entering the hilar region of the dentate gyrus. These cells were identified as granule cells or interneurons according to the physiological criteria described by Mizumori et al. (1989b). As shown in Figure 2, units were classified as inhibitory interneurons if they were activated at short latency during both field potentials elicited by paired stimulation of the perforant path ( $25 \mathrm{msec}$ interstimulus interval), that is, if activation occurred during the period of population spike inhibition within the second field response. Furthermore, classified interneurons were activated by a perforant path stimulus intensity that was well below the population spike threshold. Cells identified as granule cells were activated during the period of the population spike of the first field response elicited by paired stimulation of the perforant path, and not during the corresponding period of the second response in which the population spike was inhibited. These cells also were not activated by perforant path stimulus intensities that were below population spike threshold.

Two rates were calculated per arm of the maze, one for each radial direction in which the rat traveled. For analysis, the definition of "place field" incorporated this direction-specific firing characteristic. Thus, the "in-field" firing rate for a given cell was taken as the average rate in the preferred direction on the preferred arm, while the "out-of-field" rate reflected the mean rate during traverses of the remaining arms, as well as the preferred arm in the nonpreferred direction. It should be noted that since most place fields were restricted to only a portion of a given maze arm, the in-field rate scores underestimate the true in-field firing rate. A spatial selectivity score was calculated by dividing the difference between the in-field and out-of-field rates by their sums. This score is a nonlinear one in the sense that restriction of firing to a single arm and direction would have resulted in a score of 1.0. Note that this procedure also underestimates selectivity in cases where the field is split between 2 arms, such as the example provided in Figure 6. Thus, the estimates of spatial selectivity are relatively conservative.

Autocorrelation analyses were performed to monitor the firing patterns of different hippocampal cell types (Perkel et al., 1967). Autocorrelation functions represent the expectation density for spike discharge shortly before and after a spike at any particular time.

To assess the effects of septal inactivation, behavioral and electrophysiological data were analyzed for baseline (trials 4 and 5), tetracaine (trials 6 and 7), and recovery (trials 14 and 15) phases of the experiment.

Tetracaine injection. A $2 \%$ tetracaine solution was prepared by dissolving tetracaine hydrochloride (Sigma Chemical) in sterile $0.9 \% \mathrm{NaCl}$. When stable, isolated hippocampal units were encountered, the animal was prepared for the injection that was to occur during the recording session. The stylet was replaced with a 33 gauge stainless steel injection needle that was cut blunt. The tip of the needle protruded $1 \mathrm{~mm}$ below the tip of the guide cannula to a point just above the medial septum (see Fig. 1). The graduated polyethylene (PE20) tube that was attached to the injection needle allowed us to verify drug flow by monitoring the distance of meniscus travel. The open end of the PE tube was sealed with Parafilm to prevent leakage of tetracaine into the brain prior to injection.

After the rat completed the first 5 of 15 trials, the Parafilm was removed. The open end of the PE tube was then inserted into an adaptor that was connected to an air-pressure system (Picospritzer). Preliminary tests indicated that application of 2 pulses ( $100 \mathrm{msec}$ duration, $60 \mathrm{psi}$ ) ejected $0.5 \mu \mathrm{l}$ of fluid. The PE tube was then disconnected from the Picospritzer and the open end resealed. Throughout the entire injection procedure, it was not necessary to handle the rat. Since tetracaine appears to be relatively nontoxic (Proudfit, 1980), the effects of septal inactivation could be assessed for all cells encountered in a rat. Consequently, each cell served as its own control in this within-subjects design experiment.

\section{Results}

\section{Histology}

Results of the histological analysis verified that all recording electrode tracks traversed CAl, stratum granulosum, and the dentate hilar/CA3c region of dorsal hippocampus (see Fig. $1 A$ ). The guide cannula tip was located about $1 \mathrm{~mm}$ dorsal to the medial septum. Illustrations of the tissue damage caused by the cannula implantation and tetracaine injection can be found in 


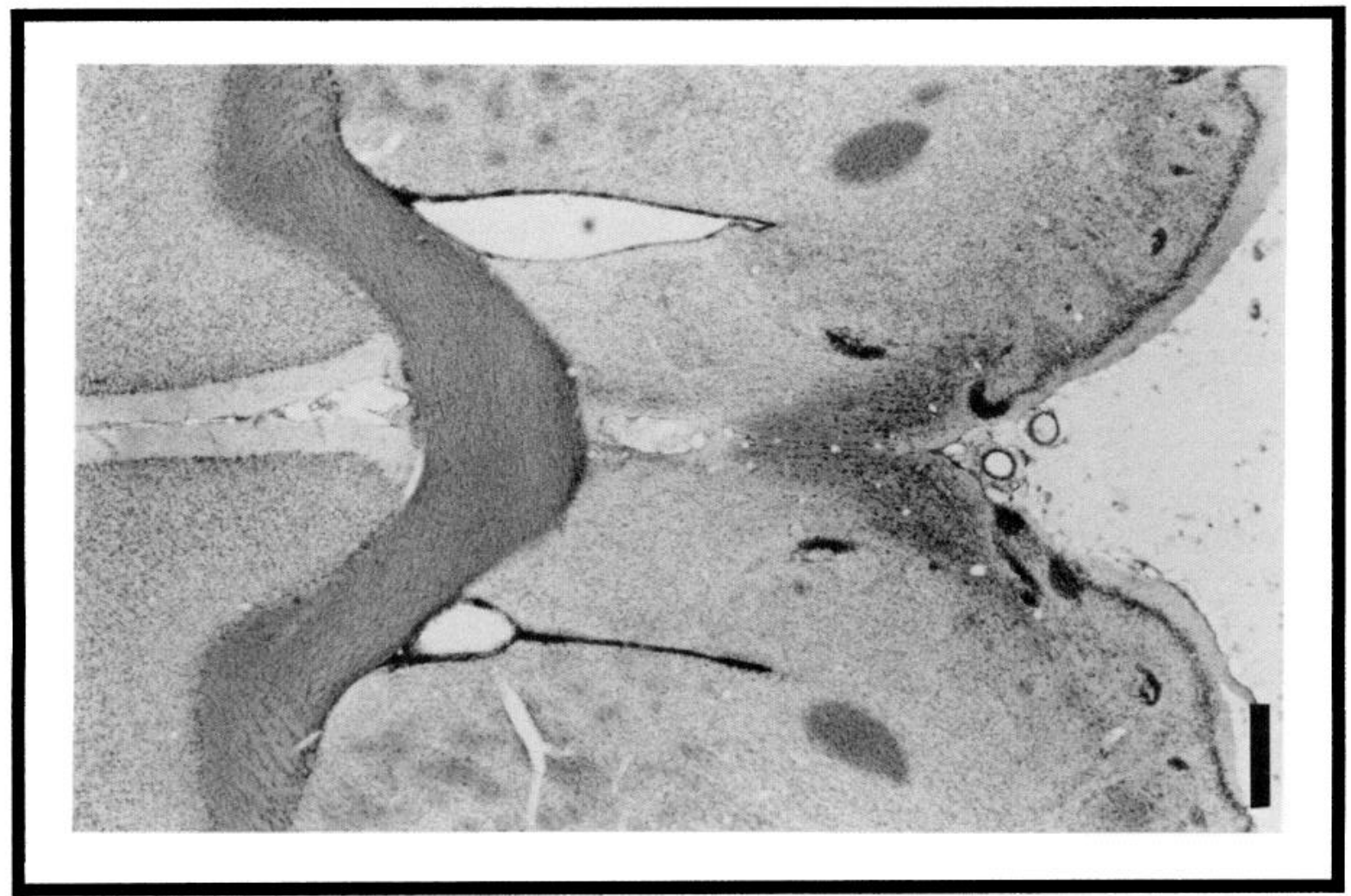

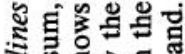

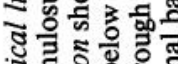

害.

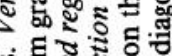

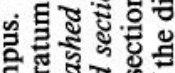

县 8

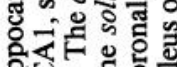

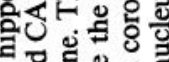

更.

论

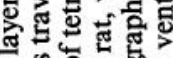

于

든.

象.

表客家

政记

可

룽

\%

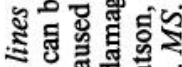

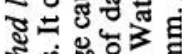

马ㅇ.을

造

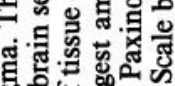

列

1
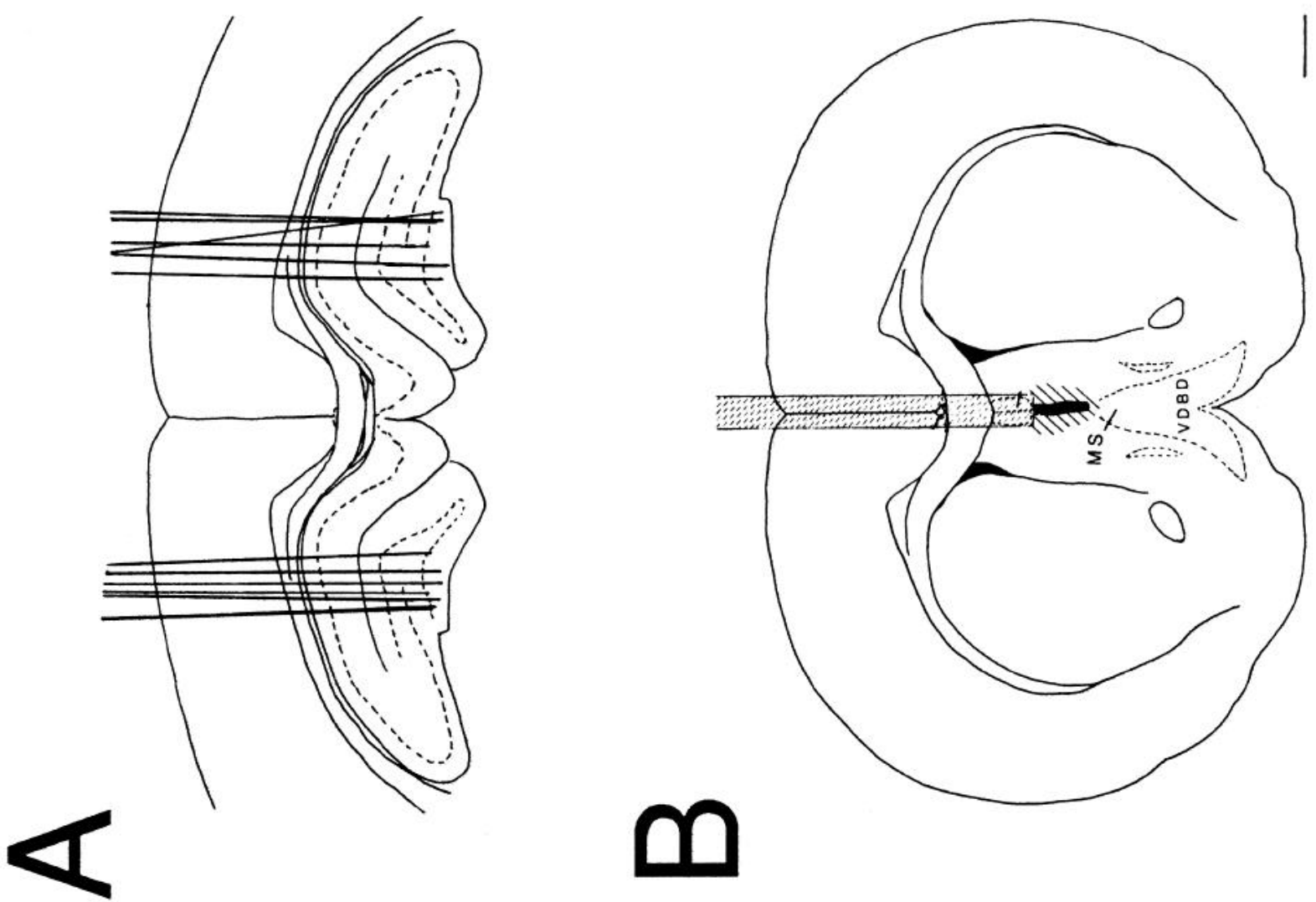

으융된현

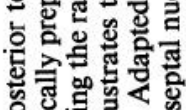

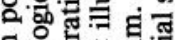

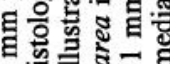

$\infty$ 局

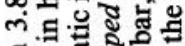

동

D

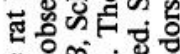

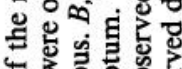

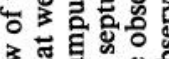

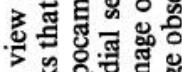

음 흘

잉

政客。

o

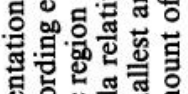

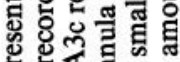

혼저웛

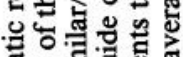

可 도ㅇㅝㅐ

奠

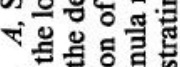

㣢宛

今. 

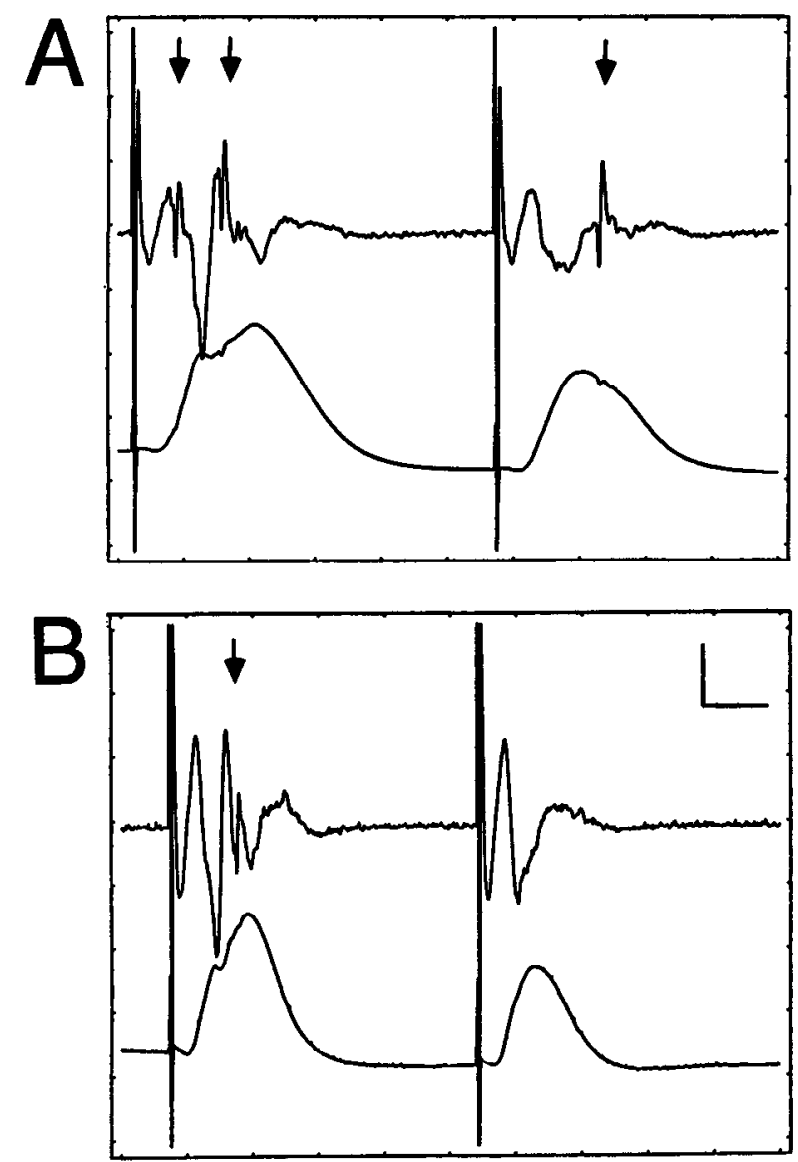

Figure 2. One criterion used to identify stratum granulosum cells as interneurons or granule cells was whether they were activated during both field potentials elicited by paired stimulation of the perforant path. Arrows indicate the activation of the unit of interest. $A$, Presumed interneurons were activated reliably during the first and second field potentials. Scale bar, $4 \mathrm{msec}, 5 \mathrm{mV}$. B, Putative granule cells, on the other hand, were activated during the period of the population spike within the first response but did not respond during the period of inhibition of the population spike in the second response. Scale bar, $5.4 \mathrm{msec}, 5$ $\mathrm{mV}$. Other measures also distinguished the 2 cell types. For example, classified interneurons were easily activated with perforant path stimulus intensities that were below population spike threshold. Granule cells were not activated with such low perforant path intensities.

Figure $1, B, C$. Implantation of the guide cannula produced slight to moderate damage along the medial wall of the anterior cingulate cortex, the induseum griseum, and the septohippocampal nucleus. The medial septum was observed to be intact in all but one case where a small amount (about $0.25 \mathrm{~mm}$ ) of the dorsal surface was damaged. Stimulating electrode tracts were located in the angular bundle.

\section{Maze performance}

Cells were recorded from a given rat over a period of about 2 months. During this time, baseline performance on the maze did not change, as indicated by the fact that the mean ( \pm SE) number of errors made during the first 5 trials of the first 10 recording sessions $(0.60 \pm 0.02)$ did not differ from the number of errors made during equivalent trials of the last 10 sessions, which occurred at least several weeks later $(0.50 \pm 0.11)$. The short-term behavioral consequences of medial septal inactivation were similar to those described for rats with permanent septal lesions (e.g., Olton et al., 1978b; Crutcher et al., 1981).

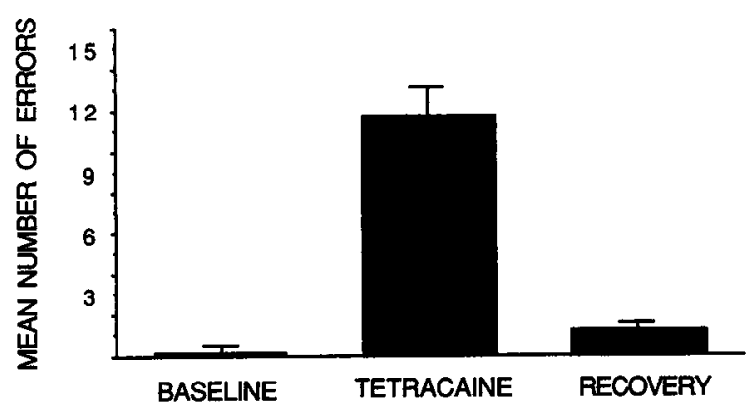

Figure 3. The short-term behavioral consequences of reversible septal inactivation are expressed in terms of the number of errors made on the maze. Baseline, During the last 2 of the 5 preinjection trials (intertrial interval $=2 \mathrm{~min}$ ), rats made on average 0.4 errors per trial. Tetracaine, During the 2 trials following injection, about 12 errors were made per trial. Recovery, By the end of the recording session, choice accuracy did not significantly differ from preinjection levels (i.e., rats made about 1.5 errors/trial).

That is, rats frequently became hyperactive and perseverative behavior was often, but not always, observed during the first minutes after injection. Figure 3 illustrates the septal inactivation-induced memory impairment in terms of the number of errors per trial. During the 2 trials before tetracaine injection, rats rarely made a single error. During the first 2 trials after injection, that is, on trials 6 and 7 , an average of 12 errors were made per trial. By the end of the recording session, the number of errors made was similar to that observed before injection. Typically, impaired choice accuracy lasted about 10-15 min. Repeated measures analysis of variance (ANOVA) revealed that the increase in errors made following septal injection was statistically significant, $F(2,46)=51.1, p<0.001$. Scheffe pairwise comparisons $(\alpha=0.05)$ confirmed that more errors were made after injection and that the number of errors made at the end of the recording session was similar to that before injection. The number of errors made following septal inactivation did not change over sessions. Rats made roughly the same number of errors during the 2 trials after injection in the first 10 recording sessions $(10.3 \pm 1.2)$ and during similar trials of the last 10 recording sessions $(10.5 \pm 1.4)$.

\section{Hippocampal EEG}

Figure 4 illustrates the baseline hippocampal $\theta$ rhythm that was observed during translational movements by the rat (i.e., movements from one place on the maze to another). Power spectra associated with this time period revealed a predominance of 7$8 \mathrm{~Hz}$ modulation, as reported previously by numerous other investigators (e.g., Vanderwolf, 1969; Feder and Ranck, 1973; Winson, 1974; Bland et al., 1975; Buzsaki et al., 1983; Fox et al., 1986). After septal inactivation and during the period of behavioral impairment, the power spectra indicated a loss of $\theta$ during movement. This result is similar to that obtained following permanent septal lesions (Green and Arduini, 1954; Donovick, 1968; Vinogradova and Brazhnik, 1978; Winson, 1978; Andersen et al., 1979; Rawlins et al., 1979; Bland and Bland, 1986). By the end of the recording session, the analog EEG traces and the corresponding power spectra were similar to those observed before injection. This pattern of effect was observed each time the septum was injected, regardless of whether the electrode was in CA1 or the dentate region. A typical example of the time course of the septal inactivation-induced change in relative power is illustrated in Figure 4. 
A

Figure 4. A, Analog examples of hippocampal EEG recorded during different phases of the experiment are illustrated in the top row. Shown below are the associated power spectra. Baseline, Before septal inactivation, clear movement-related $\theta(7-8 \mathrm{~Hz})$ was observed as the animal moved inward on maze arms. Tetracaine, After tetracaine injection into the medial septum, the EEG appeared relatively flat when the rat traversed arms of the maze, and little power was observed in the $7-8 \mathrm{~Hz}$ range. Recovery, By the end of the recording session, the $\theta$ rhythm was essentially identical to that observed before injection. $B$, Relative power within a $7-8 \mathrm{~Hz}$ range was calculated for each of the 15 training trials of an experiment, then plotted as a function of time before and after septal injection of tetracaine. The left-most bar represents power during the first trial of the session, while the bar on the far right illustrates power during the last trial. Bar locations indicate the time of the end of trials relative to the time of injection (arrow). The increased time per trial during the inactivation period reflects a corresponding increase in the number of errors. During preinjection trials $1-5$, a predominance of $\theta$ was observed in the record. Septal inactivation resulted in a dramatic reduction of $\theta$ beginning with trial 6. This effect persisted for several trials. By trial 12 , the $\theta$ power had returned to near baseline.
BASELINE

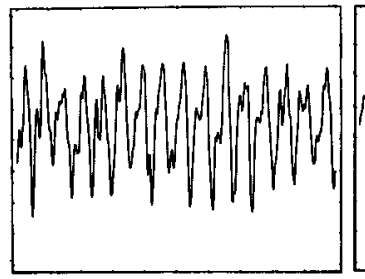

TETRACAINE

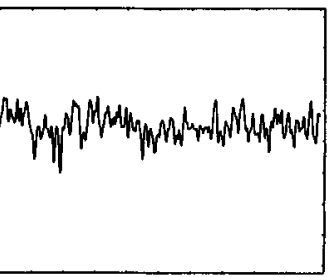

RECOVERY

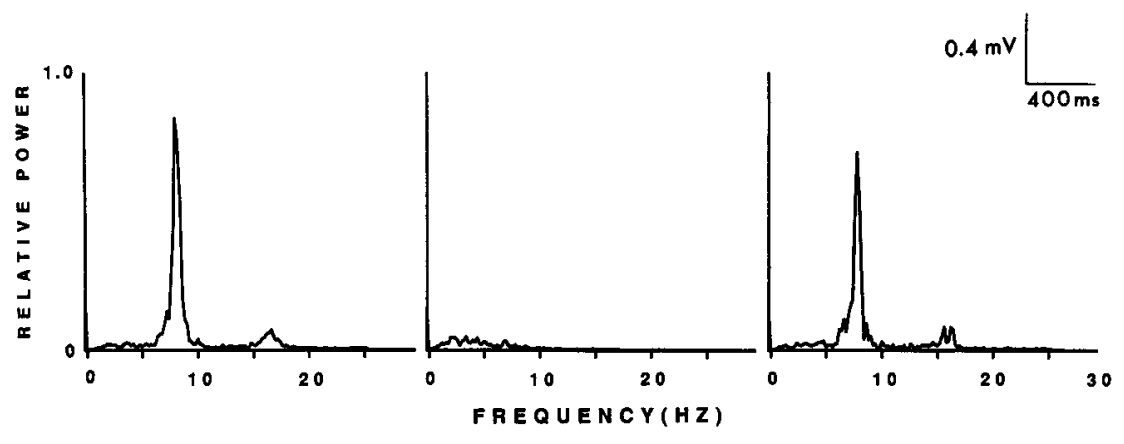

B

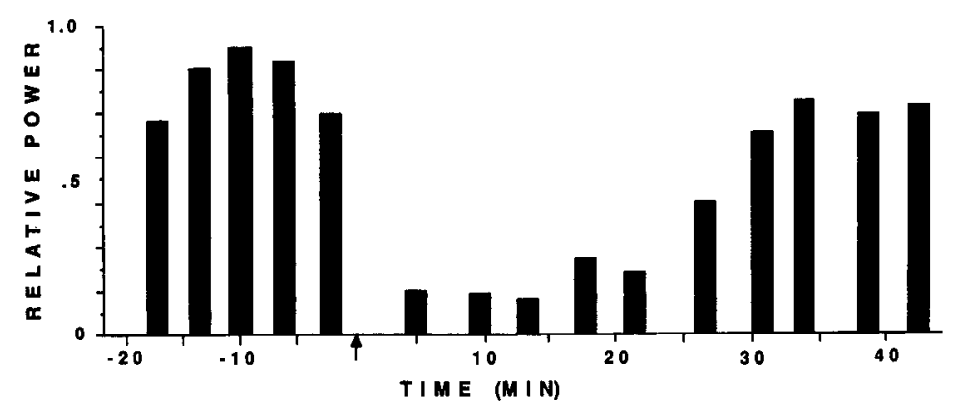

\section{CA1 complex-spike cells}

The number of CA1 and hilar/CA3c cells tested per rat is presented in Table 1. CA1 complex-spike cells (total $N=42 ; 22$ recording sessions) often discharged bursts of multiple spikes. Individual spikes within a burst were $385.2 \pm 13.3 \mu \mathrm{sec}$ in duration. This discharge pattern has been associated with hippocampal pyramidal cells (Fox and Ranck, 1975, 1981). The highest rate of discharge was observed when a rat entered a specific location on the maze from a particular direction, a finding similar to that reported by others (O'Keefe and Dostrovsky, 1971; O'Keefe, 1976; Olton et al., 1978a; McNaughton et al., 1983a; Breese et al., 1987).

Figure 5 illustrates the response of a representative CA1 place field following septal inactivation. The autocorrelation functions, also presented in Figure 5, suggest that the timing of spike discharge, and perhaps also the rhythmicity, may have been altered. It can be seen from the data presented in Figure 7 that the mean in-field or out-of-field firing rates of CAl complexspike cells did not significantly vary as a function of phase of the experiment (repeated measures ANOVA, all $p$ 's $>0.1$ ). The stability of place-specific unit discharge was further demonstrated by the lack of change in spatial selectivity scores following septal inactivation, i.e., these cells maintained the same place fields. The scatter diagrams presented in Figure $7 C$ compare spatial selectivity scores for individual units before and after tetracaine treatment.

\section{Hilar/CA3c complex-spike cells}

Hilar/CA3c complex-spike cells ( $N=53 ; 22$ recording sessions) exhibited many of the same discharge patterns shown by CA1 complex-spike cells. The hilar/CA3c cells often discharged bursts of multiple spikes, with individual spike durations of $348.6 \pm$ $7.9 \mu \mathrm{sec}$. The primary behavioral correlate of the hilar/CA3c cells was place- and direction-specific firing that was significantly more specific than that shown by CA1 complex-spike cells.

An example of the tetracaine-induced change in location specific firing and autocorrelation function of a hilar/CA3c cell is shown in Figure 6. Figure 7 compares the in-field and out-offield firing rates during the different phases of the experiment. 


\section{BASELINE}
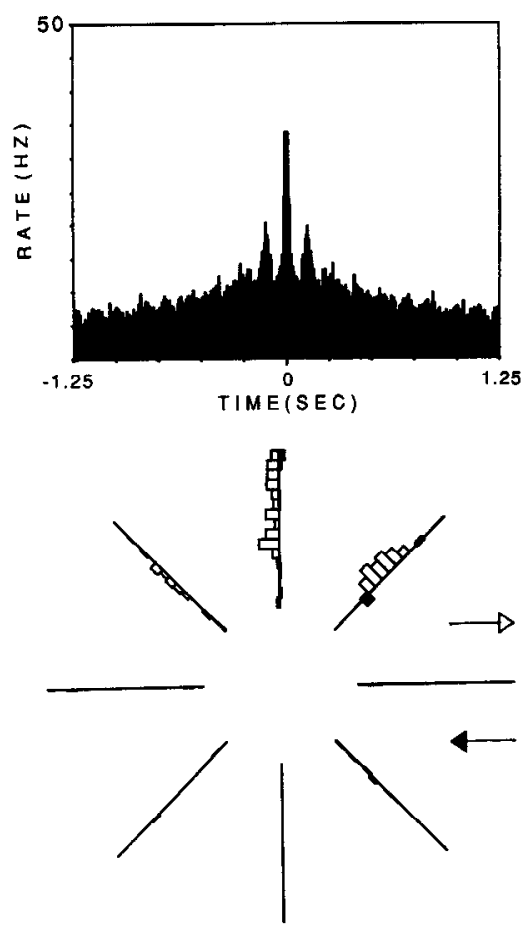

TETRACAINE
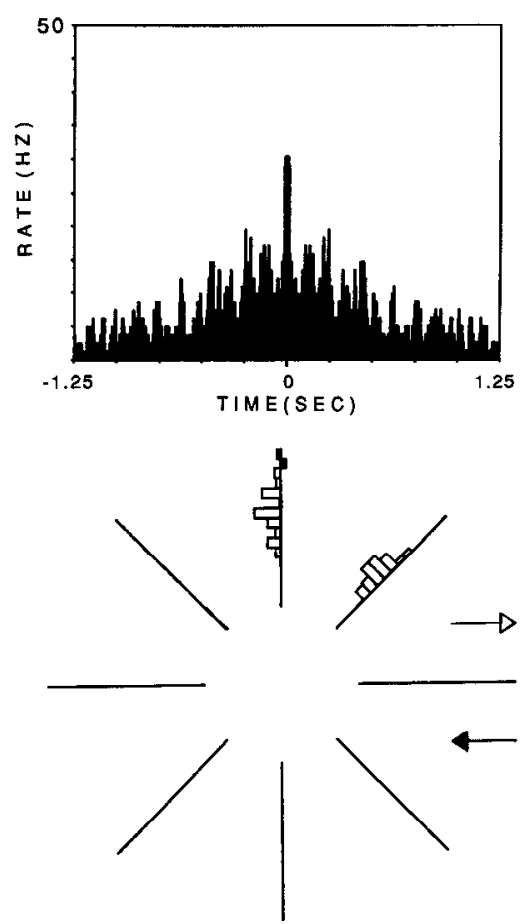

RECOVERY
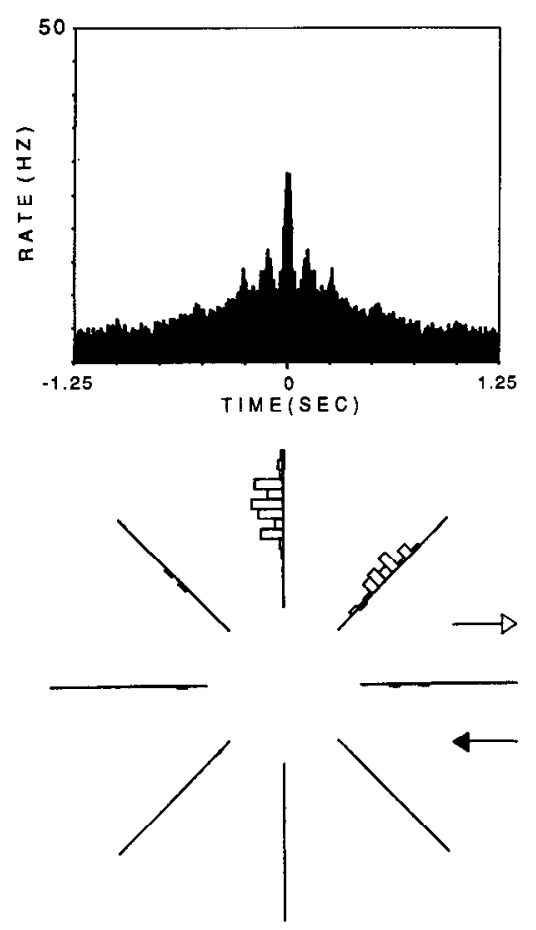

Figure 5. The upper panels illustrate autocorrelation functions of a CA1 complex-spike cell before, during, and after recovery from septal inactivation (bin width is $5 \mathrm{msec}$ ). These functions suggest that the timing of spike discharge, and perhaps rhythmicity, was altered after septal injection of tetracaine. The spatial distribution of unit discharge is shown in the lower panels. Each radial histogram illustrates the average firing rate of the cell as the rat traveled inward (closed bars) and outward (open bars) on each arm. The height of each bar is proportional to the local firing rate of the cell. Before tetracaine injection, this CAl cell preferentially fired on the north and northeast arms of the maze (maximum rate $=30 \mathrm{~Hz}$ ). The rat made 0.8 errors/trial. After injection, the rat made 16 errors, yet the cell continued to exhibit the same place field. After recovery of choice accuracy, the place field was still intact.

Although no significant change in out-of-field rate was observed, a $42 \%$ reduction of the in-field firing rate occurred following tetracaine injection $(p<0.001)$. Post hoc comparisons with the Scheffe test indicated significantly reduced in-field firing after tetracaine injection, followed by significant recovery by the end of the recording session. Spatial selectivity scores were also significantly reduced following septal inactivation $(p<0.001)$. Figure $7 C$ compares the spatial selectivity scores for individual hilar/CA3c cells before and after septal inactivation. The finding that in-field rates were reduced while out-of-field rates remained stable is consistent with observations that, during recovery, the gradual increase in hilar/CA $3 c$ unit discharge was observed only when the rat passed through the cell's original place field.

\section{CA1 theta cells}

CAl theta cells ( $N=13 ; 13$ recording sessions) discharged short duration $(221.4 \pm 12.4 \mu \mathrm{sec})$ single spikes that were often rhythmically modulated, as shown in Figure 8. When compared with CA1 complex-spike cells, CA1 theta cells exhibited relatively little spatially selective firing (see Fig. 8). As described by others (e.g., Ranck, 1973; Fox and Ranck, 1975; O'Keefe, 1976; McNaughton et al., 1983a), the most obvious behavioral correlate of CA1 theta units was voluntary movement. When the rat remained still at the ends of the arms, theta cells fired at their lowest rate (about $8 \mathrm{~Hz}$ ). As the rat turned around to face the center of the maze, the rate began to increase. For many of the cells, the firing rate continued to increase to about $15 \mathrm{~Hz}$ until the rat passed through the maze center. Finally, as the rat approached the end of the next arm selected, the rate declined. The change in firing rate as a function of movement about the maze is summarized in Figure 10. This movement-induced alteration in spontaneous activity was statistically significant [repeated-measures ANOVA, $F(4,12)=7.56, p<0.01]$. Post hoc comparisons (Scheffe test) indicated that the firing rate of the cell as the rat traversed either maze arms or the center platform was significantly higher than when the rat remained still at the arm ends. The perievent histograms and corresponding rasters of Figure 8 illustrate the general movement sensitivity for one theta cell.

Septal inactivation eliminated the original pattern of rhythmic discharge (see Fig. 8). In addition, septal injection of tetracaine reduced the mean overall firing rate of $\mathrm{CA} 1$ theta cells from

Table 1. Number of cells tested per rat following septal inactivation

\begin{tabular}{lcc} 
Rat & CAl & Hilar/CA3c \\
\hline 1 & 8 & 12 \\
2 & 10 & 12 \\
3 & 5 & 10 \\
4 & 6 & 3 \\
5 & 7 & 6 \\
6 & 6 & 10 \\
\hline
\end{tabular}




\section{BASELINE}
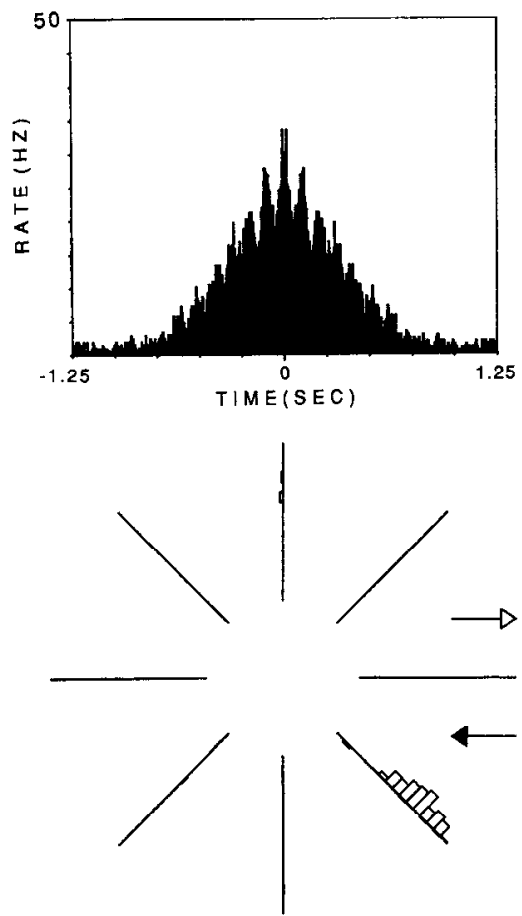

TETRACAINE
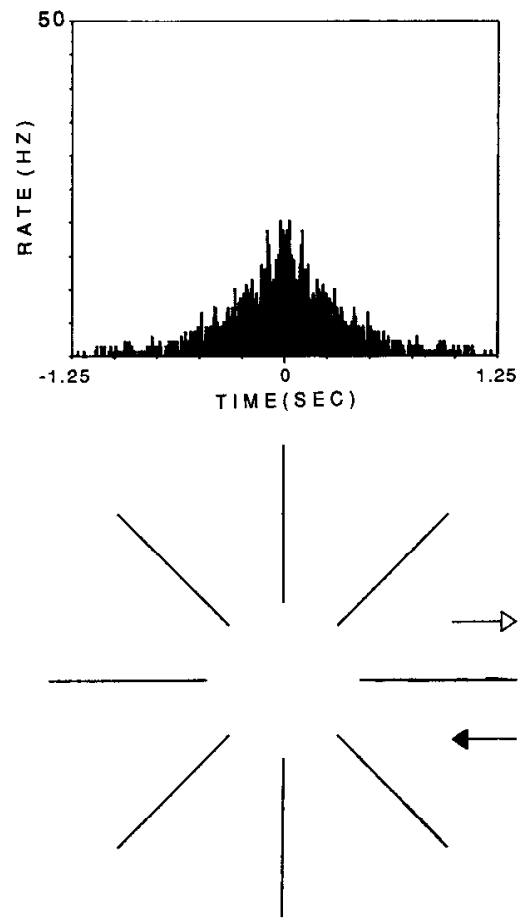

RECOVERY
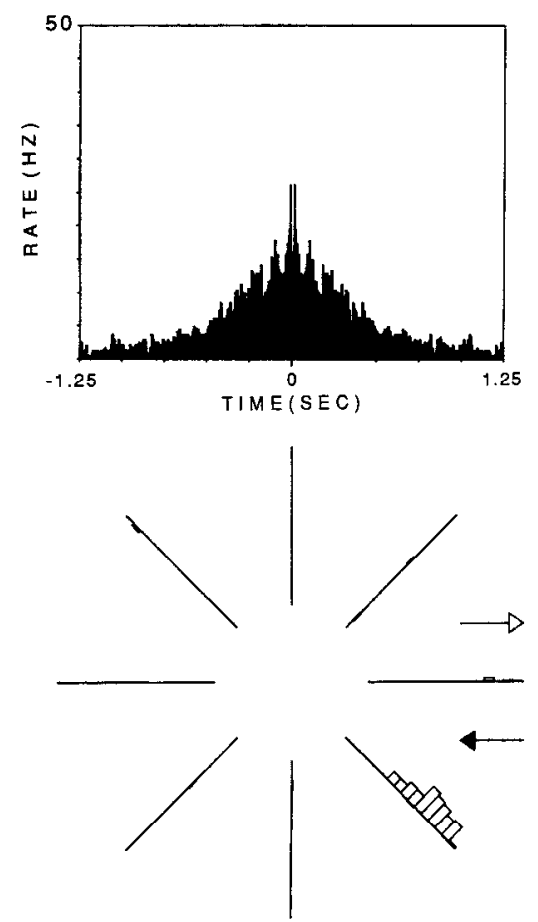

Figure 6. Autocorrelation functions illustrate the septal inactivation-induced reduction in firing rate and temporally patterned discharge of a hilar/ CA3c complex-spike cell. The accompanying radial histograms show that the original place field on the southeast arm of the maze disappeared after tetracaine injection (maximum rate $=65 \mathrm{~Hz}$ ). By the end of the recording session, the place field was again observed on the southeast arm of the maze.

about 13.9 to $7.6 \mathrm{~Hz}[F(1,12)=4.85, p<0.05]$. Close examination of Figure 10 reveals that a large portion of the rate reduction can be attributed to the fact that the theta cells were less sensitive to different movements made by the rat. That is, the firing rate as the rat traversed the maze was no longer significantly different from the rate associated with periods of relative immobility at arm ends. The perievent histograms of Figure 8 illustrate the tetracaine-induced reduction in movementrelated discharge, as well as the subsequent recovery.

\section{Stratum granulosum cells}

Cells recorded in stratum granulosum (SG; $N=28 ; 17$ recording sessions) fired single spikes (288.6 $\pm 27.5 \mu \mathrm{sec}$ in duration) that were frequently rhythmically modulated (see Fig. 9 for an example). Similar to the CA1 theta cells, SG cells did not exhibit the degree of spatially selective discharge shown by the complexspike cells. Instead, the clearest behavioral correlate for SG cells was translational movements on the maze, with the peak firing rate coincident with traverses across the central platform. The change in rate as a function of specific movements by the animal was statistically significant [see Fig. $10 ; F(4,27)=12.60, p<$ $0.01]$.

Tetracaine injection into the medial septum produced an effect on SG cells that was similar to that observed for CA1 theta cells (Fig. 8). The rhythmic pattern of unit discharge was eliminated. Additionally, the overall mean discharge rate was significantly reduced from 7.5 to $4.0 \mathrm{~Hz}[F(2,27)=6.73, p<$ $0.01]$. Figure 10 shows that the lower overall mean rate was entirely due to a reduction in movement sensitivity. That is, while SG cell firing rates during periods of relative immobility at the arm ends were similar before and after tetracaine treatment, the usual increase in firing during movements across the maze was no longer observed after tetracaine injection.

Recovery of SG unil firing typically preceded behavioral recovery. During unit recovery, it was typical to observe a gradual increase in the overall firing rate by about $15 \mathrm{~min}$ postinjection. The increase in unit discharge was often first observed when the rat crossed the center of the maze. Eventually, the cell would also exhibit general movement sensitivity. For those units exhibiting rhythmic discharge before injection, rhythmicity returned after the frequency of cell discharge approached preinjection levels. In these instances, complete behavioral recovery usually occurred after resumption of rhythmic firing.

Of the $28 \mathrm{SG}$ cells recorded, 11 were tested for identification as interneurons or granule cells (Mizumori et al., 1989b). Similar to the pattern of effects observed in anesthetized animals (Mizumori et al., 1989a, b) the mean firing rate of putative granule cells was exceedingly low $(n=4 ; 0.01 \pm 0.001 \mathrm{~Hz})$ and was clearly different from the rate of classified interneurons $(n=7$; $12.8 \pm 4.8 \mathrm{~Hz} ; p<0.05)$. However, the firing rates in the present study were considerably lower than those observed under anesthesia, a finding consistent with the observation that most hippocampal neurons actually increase their rate under anesthesia (Thompson and Best, 1988). Indeed, it is worth emphasizing that the rates for cells classified as granule cells in this study were so low that these cells would probably have been overlooked if not for their activation by perforant-path stimulation. The firing rate of classified interneurons showed the 
type of movement sensitivity illustrated in Figures 8-10. Septal inactivation reduced the average firing rate of these cells by about $50 \%$. No clear behavioral correlates or tetracaine effects were observed for classified granule cells. This result was probably influenced by the extremely low spontaneous discharge rate of these cells. The large difference in firing rates of identified granule cells and interneurons led us to believe that most, if not all, of the SG cells recorded in the first 4 rats of this study were probably interneurons. The mean baseline firing rate of these cells was $7.2 \mathrm{~Hz}$. Granule cells that might have appeared in the unit record of these animals were most likely overlooked because of their extremely low spontaneous firing rate.

\section{Discussion}

The present investigation of medial septal influences on hippocampal single-unit activity has revealed new relationships between performance on a spatial task and hippocampal physiology. Behaviorally, reversible septal inactivation resulted in a large but transient increase in the number of errors made on the radial maze, a finding similar to that observed following permanent septal damage (e.g, Winson, 1978). During this period of behavioral impairment, the specificity of CA1 place fields was maintained even though the movement-sensitive $\theta$ rhythm in the EEG was eliminated. Furthermore, preserved CA1 placespecific discharge was observed despite a substantial septal inactivation-induced reduction in the behavioral correlates and firing rates of dentate gyrus/CA3c cells. The latter result was surprising in light of recent anatomical results which show that the half of CAl closest to the subiculum, from which most of our CA1 cells were recorded, receives most of its input from CA3c (Ishizuka et al., 1989), which was wherc our CA3 data were recorded. A similar pattern of unit effects on mean discharge rate has been observed in anesthetized animals (Mizumori et al., 1989a). Thus, the reversible inactivation of afferents appears to be a viable and, in many respects, a technically advantageous method for studying the functional connectivity of the hippocampus.

Although it is possible tentatively to identify many of the units recorded in hippocampus according to electrophysiological criteria (e.g., Fox and Ranck, 1975, 1981; Mizumori et al., $1989 \mathrm{~b}$ ), the anatomy of the septohippocampal afferent system is sufficiently complex to preclude a straightforward explanation of septal inactivation effects. For example, anatomical studies indicate that ChAT-positive septal afferents form symmetric and asymmetric synapses on pyramidal cells, granule cells, and interneurons (Rose et al., 1976; Chandler and Crutcher, 1983; Frotscher and Leranth, 1985). GABAergic septal afferents (Kohler et al., 1984) appear to contact primarily interneurons (Freund and Antal, 1988), although the latter authors also observed a few contacts with granule and pyramidal cells. Substance P (Vincent and McGeer, 1981) and oxytocin and vasopressin (Sofroniew, 1985a, b) have also been associated with septohippocampal afferents. Thus, it appears that the response of hippocampal cells to septal inactivation may have involved a variety of mechanisms. That septal inactivation did not affect the firing rate during periods of relative immobility suggests that control of interneuron activity during still conditions might not involve the medial septum.

In addition to influences on septohippocampal afferents per se, septal inactivation may have affected dentate gyrus/CA3c cell firing rates via other mechanisms. In particular, inactivation of septal efferents to layer II of entorhinal cortex may have
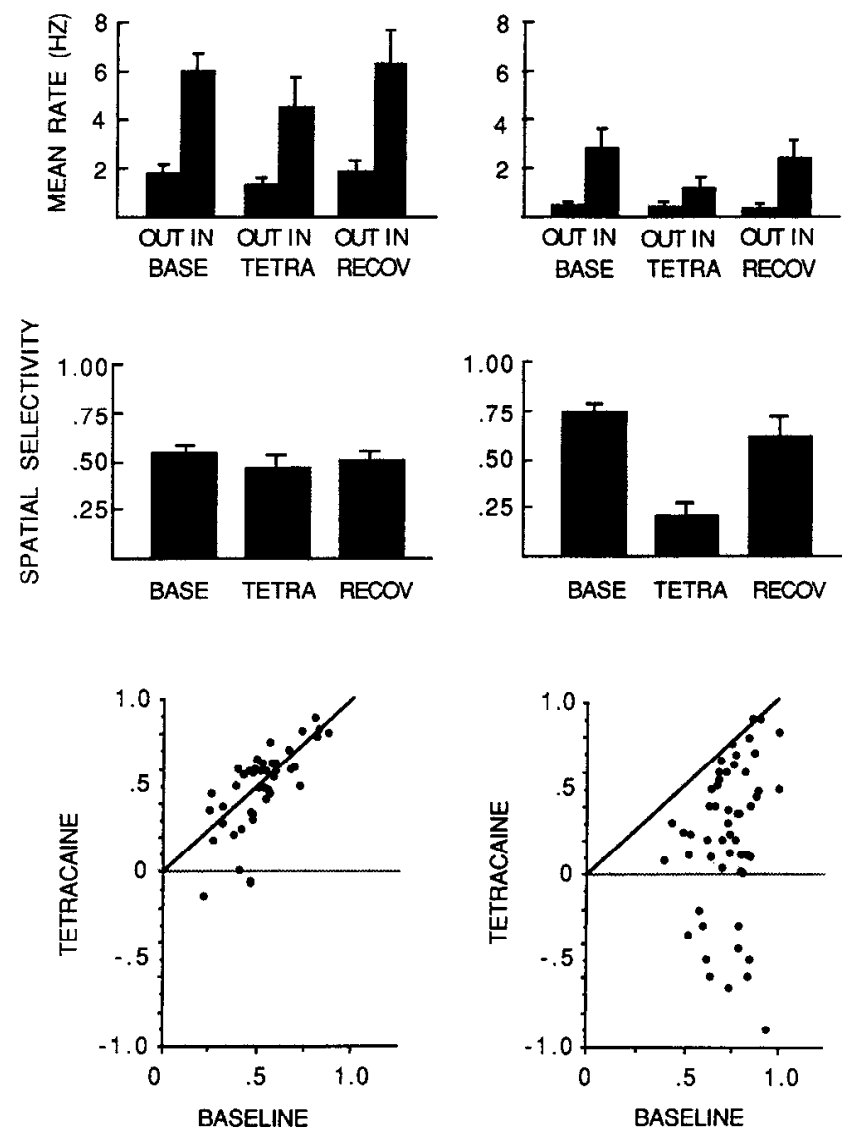

SPATIAL SELECTIVITY SCORES

Figure 7. Top and middle, Mean ( $\pm \mathrm{SE})$ spontaneous firing rate on the maze arm containing the place field $(I N)$ is compared with the rate as the rat traversed the remaining arms (OUT) for different phases of the experiment (baseline, tetracaine, recovery). The out-of-field rates did not change significantly following septal inactivation for either CA1 or hilar/CA $3 c$ cclls. In contrast, the in-ficld rates for CA1 and hilar/CA3c cells were differentially affected by the tetracaine treatment. The infield firing rates of CA1 cells were not significantly affected by septal inactivation, whereas similar rates of hilar/CA3c cells were significantly reduced. The spatial selectivity scores, which take into account both inand out-of-field rates (see text), further illustrate that place-specific firing of $C A 1$ cells was preserved during the period of behavioral impairment (Fig. 3) and reduction of hippocampal $\theta$ rhythm (Fig. 4). In contrast, spatial selectivity of hilar/CA3c cells was not maintained following tetracaine injection. Bottom, Scatter diagrams comparing the spatial selectivity scores before and after septal inactivation for CA1 and hilar/ $\mathrm{CA} 3 \mathrm{c}$ cells. Individual dots represent data from single cells. The different patterns of distribution illustrate that, while the in-field firing rate of hilar/CA3c complex-spike cells was often reduced more than the outof-field rates, the in-field and out-of-field rates of CAl complex-spike cells were relatively unaffected following septal inactivation. The diagonal line represents the expected relationship under the null hypothesis of no effect of tetracaine on spatial selectivity.

compromised the output from layer II to the dentate gyrus (Steward and Scoville, 1976; Alonso and Kohler, 1984). Furthermore, it is likely that inactivation of the many fibers of passage in the vicinity of the medial septum also played a role. Candidate fiber systems include those originating in locus coeruleus (e.g., Jones and Moore, 1977), the medial and dorsal raphe (e.g., Conrad et al., 1974), the hypothalamus (e.g.. Swanson, 1976; Saper et al., 1979; Haglund et al., 1984), the later- 
BASELINE
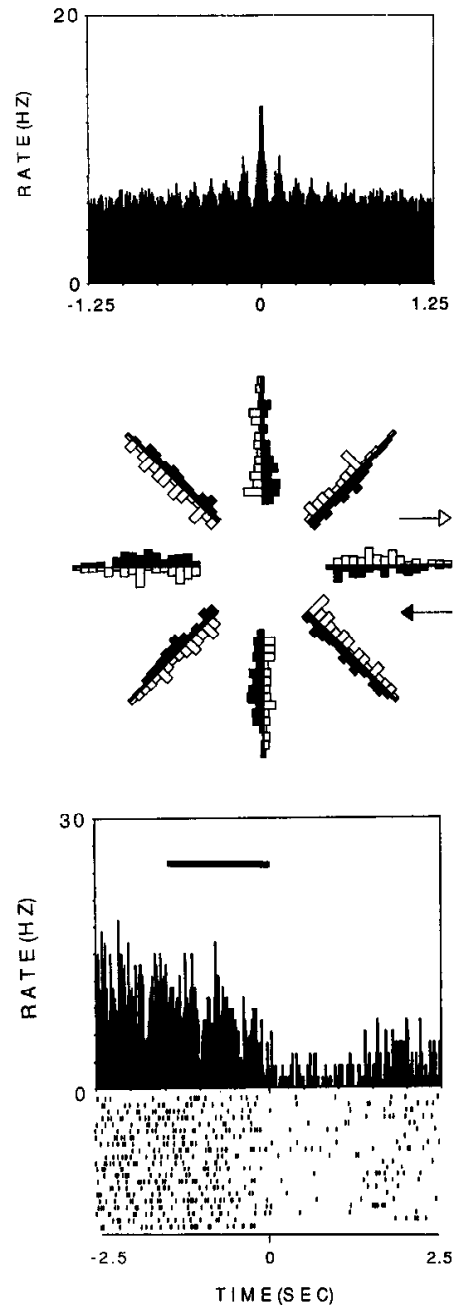

TETRACAINE
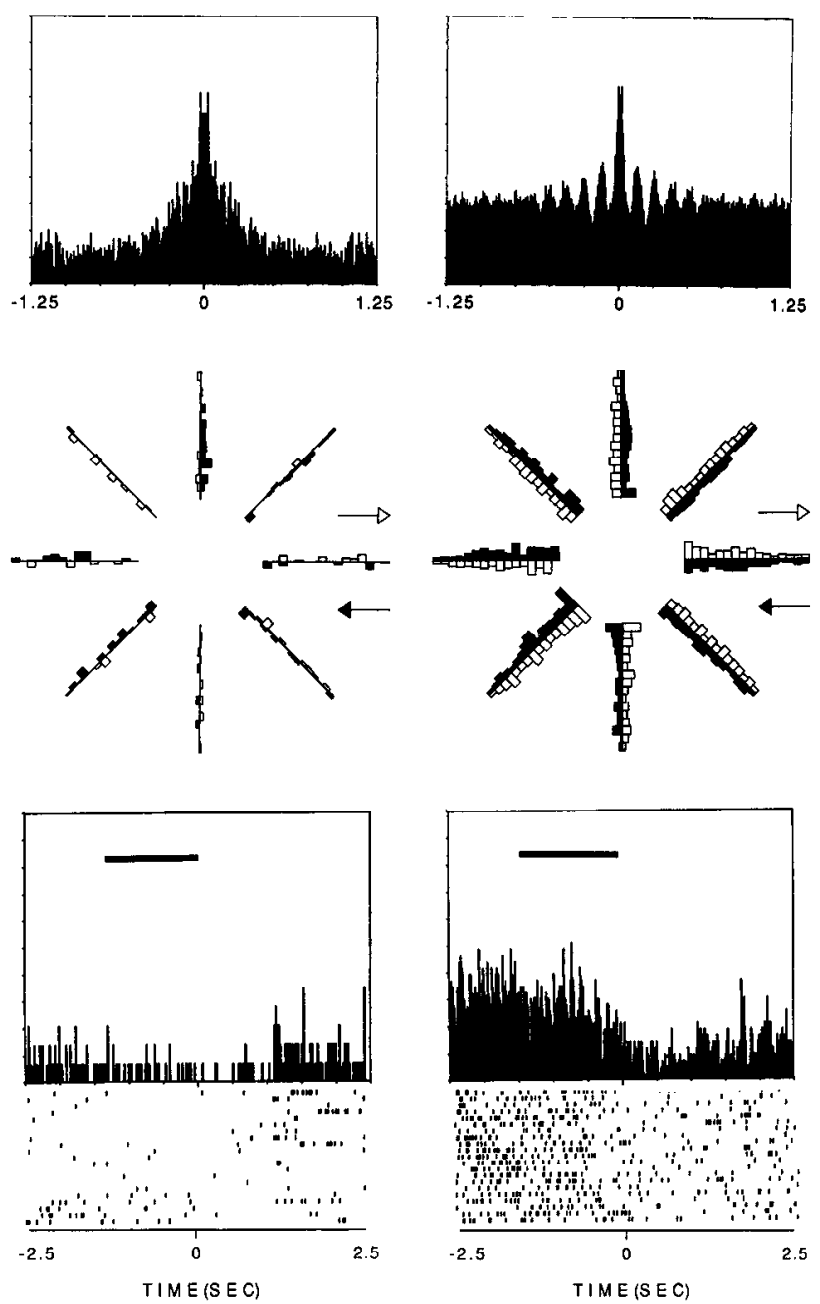

RECOVERY

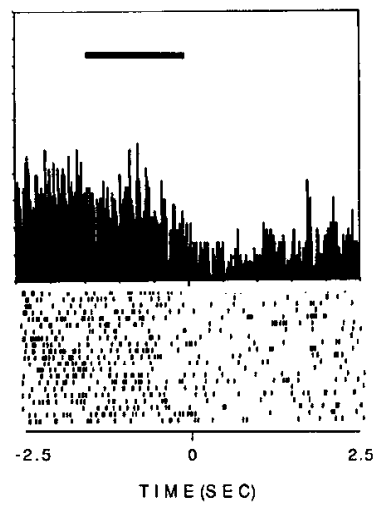

odorsal tegmental nucleus (Satoh and Fibiger, 1986), and possibly the vertical limb of the diagonal band (Mesulam et al., 1983).

It might be argued that tetracaine spread to the recording site and that this was the cause of the observed large reduction in firing rates. This possibility seems rather unlikely, however, for the following reasons: we have previously shown that injection of a local anesthetic $1 \mathrm{~mm}$ above the medial septum does not change the activity of hippocampal units that were altered when injections were made directly into the septum (Mizumori et al., $1989 a$ ). The latter result is consistent with quantitative analysis of the spread of effects of a local anesthetic injection into the CNS (Schiller et al., 1979; Sandkuhler et al., 1987). Furthermore, if tetracaine leaked to hippocampal recording sites, we would have expected a consistent decrease in firing for all cells recorded. On the contrary, simultaneously recorded cells frequently responded differently to a given injection, and a few responded with increases in firing rate. Elevated dentate unit activity has also been observed following inactivation of the contralateral hilar region (Mizumori et al., 1989a). Thus, it seems clear that the unit results were not mediated by unintentional spread of tetracaine. However, as indicated above, the precise mechanisms of action remain to be determined.
One important caveat must be applied to the interpretation of the behavioral results of this study, as well as to many other experimental investigations of learning and memory. The standard procedure for determining the selectivity of a memory impairment involves assessing a subject's ability to learn different tasks. While this approach is appropriate for evaluating the extent of preserved learning abilities (including whether the impairment might be due to a disruption of performance factors such as motor coordination, sensory acuity, etc.), it does not address the issue of whether poor choice accuracy results from an inability to carry out the normal cognitive operations required for the task or whether the subject performs poorly because of the inappropriate utilization of a different cognitive strategy. With reference to the present experiment, we have prcliminary cvidence which suggests that the effects of septal inactivation are selective in that such treatment does not impair simple auditory discrimination performance in an operant chamber (S. J. Y. Mizumori et al., unpublished observations). This implies that tetracaine-treated animals are capable of accurately performing sensory discriminations in tasks with different behavioral (i.e., nonspatial) requirements. Furthermore, the fact that the rats readily ran down arms and consumed the reward indicates that neither memory for the procedural aspects 


\section{BASELINE}
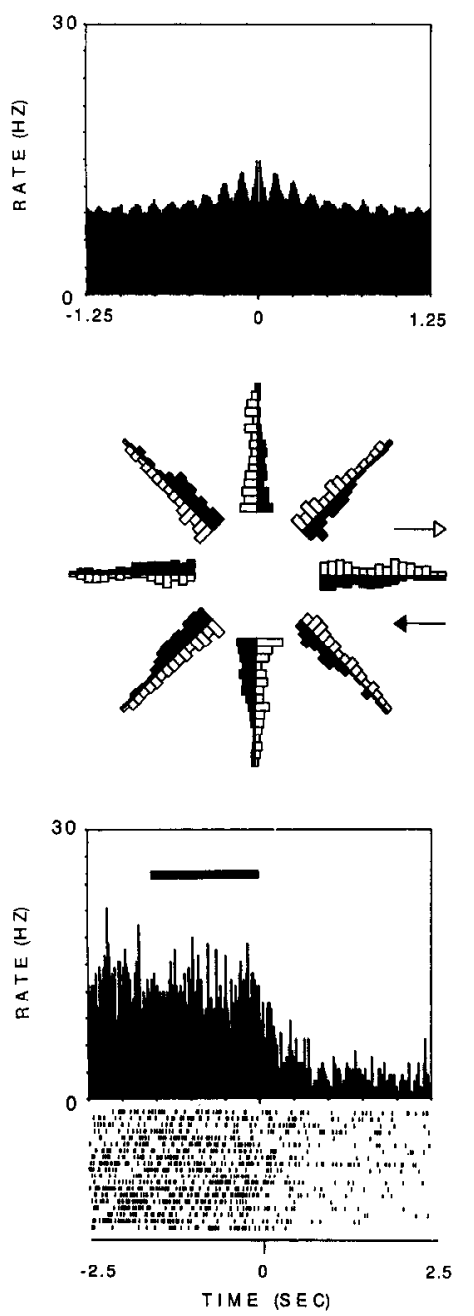

TETRACAINE
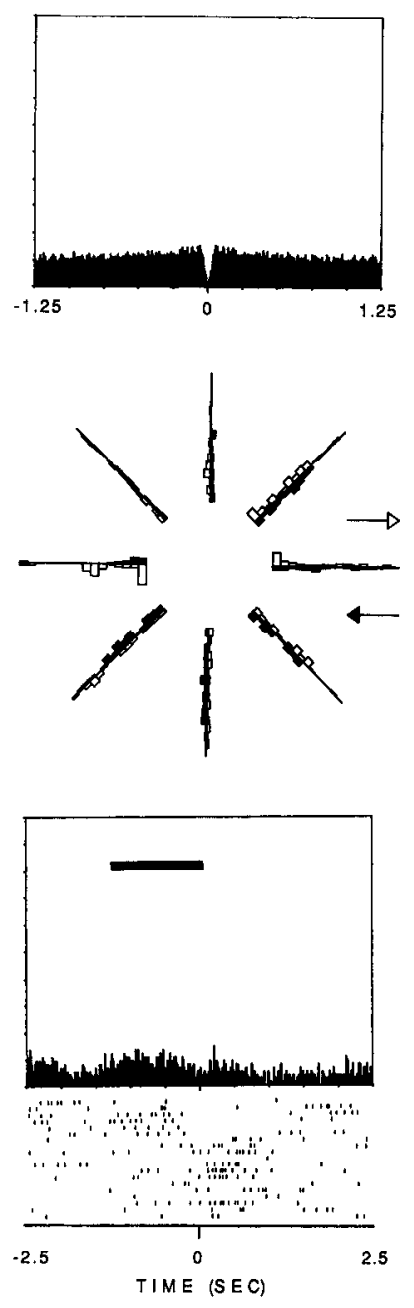

of the task nor motor performance were disrupted. While these considerations fall short of allowing us to conclude that poor choice accuracy on the radial maze following tetracaine injections represents a unique disruption of the spatial memory system, they do tend to support this hypothesis.

To the extent that the tetracaine-treated rats of this study suffered a spatial memory impairment, several possible interpretations of different aspects of these data are of potential theoretical value for understanding hippocampal function. The finding that the specificity of CAl place fields did not change during periods of memory impairment indicates that place-specific cell firing is not sufficient to support good performance on a spatial task. That the main output cells of hippocampus (i.e., CA1) appeared to function normally following septal inactivation may have implications for strategies to alleviate memory deficits due to cholinergic denervation of hippocampus by the grafting of cholinergic cells in hippocampus. That place-specific firing of CA1 cells was not related to the integrity of hippocampal $\theta$ rhythm suggests that normal rhythmic oscillations of cellular activity do not importantly influence CA1 pyramidal cell responses to spatially relevant inputs.

The finding that CA1 place fields showed little, if any, change during periods of lowered spontaneous activity and reduced
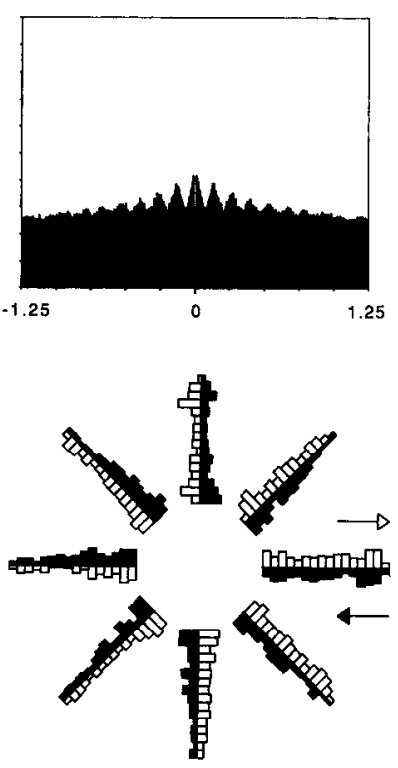

Figure 9. Autocorrelation functions, radial histograms (maximum rate $=20$ $\mathrm{Hz}$ ), and perievent histograms of a stratum granulosum cell illustrate that the baseline discharge pattern and behavioral correlates were similar to those observed for CAl theta cells (Fig. 7). Following septal inactivation, the original rhythmic firing pattern was eliminated and the overall rate was drastically reduced. Furthermore, the movement-sensitive nature of cell discharge was no longer observed. By the end of the recording session, the rhythmic firing pattern, the mean firing rate, and the movement-sensitivity of the cell resembled that observed during the baseline period.

place specificity by dentate gyrus/CA3c units is consistent with the prediction that reduction of CA3 output should leave spatially selective firing by CA1 cells intact (see introductory remarks). CA1 pyramidal cell output may have been preserved because of a decline in feedforward inhibition that was proportional to the reduced rates in CA3c. This explanation implies that the remaining inputs from $\mathrm{CA} 3 \mathrm{c}$ provided adequate spatially relevant information to $\mathrm{CA} 1$ pyramidal cells to allow apparently normal place-specific firing to occur. This interpretation is congruent with Marr's $(1969,1971)$ hypothesis that feedforward inhibition effectively divides the excitation of principal cells by an amount that is proportional to the number of active (excitatory) afferents. Associative recall and pattern completion were hypothesized to rely on such feedforward inhibitory processes. An elaboration of this hypothesis in terms of recent data on hippocampal physiology can be found elsewhere (McNaughton and Morris, 1987; McNaughton and Nadel, 1989).

An alternative explanation for the finding of maintained CA1 place specificity during the period of reduced dentate gyrus and CA $3 c$ discharge is that spatially relevant afferents arrive in CA1 via routes that are not included in the traditional "trisynaptic loop" of Andersen et al. (1971). Indeed, anatomical studies have demonstrated direct projections from entorhinal cortex to CA1 
BASELINE TETRACAINE MIV RECOVERY

CA1 THETA CELLS

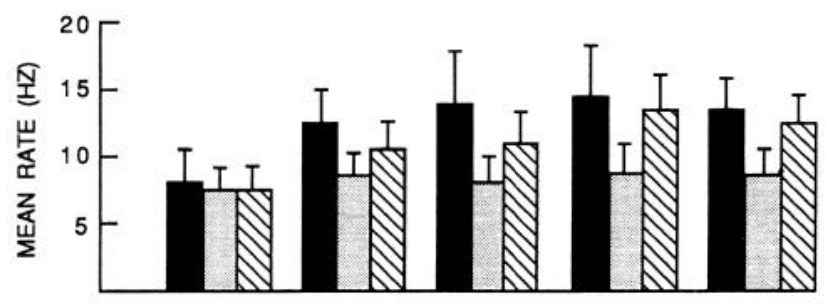

STRATUM GRANULOSUM CELLS

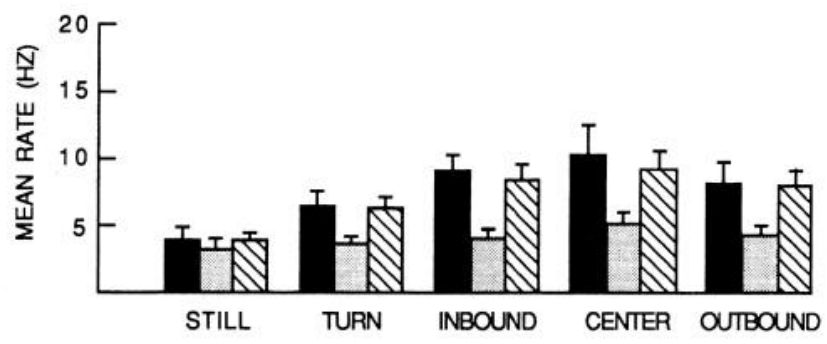

Figure 10. Mean $( \pm \mathrm{SE})$ firing rate of $\mathrm{CA} 1$ theta and stratum granulosum cells as a function of behavior of the animal during different phases of the experiment. Before injection, these cells fired at their lowest rate when rats were relatively immobile $(S T I L L)$ at the arm ends. As rats turned to face the center of the maze (TURN), the firing rate began to increase. Many cells continued to increase their firing rate as rats moved inbound on the maze arms (INBOUND) and crossed the central platform (CENTER). The firing rate during outward movements on maze arms (OUTBOUND) was similar to that observed during inward movements. Septal inactivation significantly reduced the overall firing rate of both types of cells. The rate reductions were almost entirely due to loss of movement-related firing, with little or no change occurring during the still condition.

(Steward, 1976; Steward and Scoville, 1976; Kohler, 1986; Swanson and Kohler, 1986; Witter et al., 1988).

Several different but not necessarily exclusive explanations are possible for the failure of accurate spatial firing in CA1 to support choice accuracy on the radial maze. One possibility is that choice accuracy may be highly sensitive to relatively minor changes in the rate and temporal pattern of these cells. Another possibility is that basal forebrain output to other cortical areas may have been disrupted and that this was the dominant cause of the performance deficit. A more likely explanation, however, relates to the possibility that outflow to the cortex from the hippocampus itself may have been disrupted. While our data do suggest that the principal cells in CA1 may have been able to carry out normal spatial coding functions, despite reduced input from the dentate/CA3c region, by implementing pattern completion (Marr, 1969, 1971; McNaughton and Morris, 1987; McNaughton and Nadel, 1989), it is well known that the medial septum projects rather heavily to the subicular complex, the main relay for CA1 output to the cortex (Hjorth-Simonsen, 1973; Swanson et al., 1978). Suppression of activity in this structure may have resulted in a functional disconnection of an intact memory system in CAl from its cortical targets. The same interpretation, of course, may be applicable to previous inves- tigations of the behavioral consequences of permanent septal lesions.

\section{References}

Alonso, A., and C. Kohler (1984) A study of the reciprocal connections between the septum and the entorhinal area using anterograde and retrograde axonal transport methods in the rat brain. J. Comp. Neurol. 225: 327-343.

Alvarez-Leefmans, F. J., and A. R. Gardner-Medwin (1975) Influences of the septum on the hippocampal dentate area which are unaccompanied by field potentials. J. Physiol. (Lond.) 249: 14P-16P.

Andersen, P., T. V. P. Bliss, and K. Skrede (1971) Lamellar organization of hippocampal excitatory pathways. Exp. Brain Res. 13: 222238.

Andersen, P., B. H. Bland, T., Myhrer, and P. A. Schwartzkroin (1979) Septohippocampal pathway necessary for dentate theta production. Brain Res. 165: 13-22.

Barea, E. J., M. R. Hickey, and D. C. Smith (1988) Hippocampal inactivation effects on spatial memory. Soc. Neurosc. Abstr. 14: 233.

Becker, J. T., J. A. Walker, and D. S. Olton (1980) Neuroanatomical bases of spatial memory. Brain Res. 200: 307-321.

Bilkey, D. K., and G. V. Goddard (1985) Medial septal facilitation of hippocampal granule cell activity is mediated by inhibition of inhibitory interneurons. Brain Res. 361: 99-106.

Bilkey, D. K., and G. V. Goddard (1987) Septohippocampal and commissural pathways antagonistically control inhibitory interneurons in the dentate gyrus. Brain Res. 405: 320-325.

Bland, B. H. (1986) The physiology and pharmacology of hippocampal formation theta rhythms. Prog. Neurobiol. Lond. 26: 1-54.

Bland, B. H., and S. K. Bland (1986) Medial septal modulation of hippocampal theta cell discharges. Brain Res. 375: 102-116.

Bland, B. H., P. Andersen, and T. Ganes (1975) Two generators of hippocampal theta activity in rabbits. Brain Res. 94: 199-218.

Breese, C. R., R. E. Hampson, and S. A. Deadwyler (1987) Direction contingent firing of hippocampal place cells. Soc. Neurosc. Abstr. 13: 608.

Buzsaki, G., L.-W. S. Leung, and C. H. Vanderwolf (1983) Cellular basis of hippocampal EEG in the behaving rat. Brain Res. Rev. 6 : 139-171.

Chandler, J. P., and K. A. Crutcher (1983) The septohippocampal projection in the rat: An electron microscopic horseradish peroxidase study. Neuroscience 10:685-696.

Conrad, L. C. A., C. M. Leonard, and D. W. Pfaff (1974) Connections of the median and dorsal raphe nuclei in the rat: An autoradiographic and degeneration study. J. Comp. Neurol. 156: 179-206.

Crutcher, K. A., R. P. Kesner, and J. M. Novak (1981) Medial septal lesions, radial arm maze performance, and sympathetic sprouting: A study of recovery of function. Brain Res. 210: 115-128.

DeCastro, J. M. (1974) A selective spatial discrimination deficit after fornicotomy in the rat. Behav. Biol. 12: 373-382.

Donovick, P. J. (1968) Effects of localized septal lesion on hippocampal EEG activity and behavior in rats. J. Comp. Physiol. Psychol. 66: 569-578.

Fantie, B. D., and G. V. Goddard (1982) Septal modulation of the population spike in the fascia dentata produced by perforant path stimulation in the rat. Brain Res. 252: 227-237.

Feder, R., and J. B. Ranck, Jr. (1973) Studies on single neurons in dorsal hippocampal formation and septum in unrestrained rats. Part II. Hippocampal slow waves and theta cell firing during bar pressing and other behaviors. Exp. Neurol. 41: 532-555.

Flicker, C., and M. A. Geyer (1982) Behavior during hippocampal microinfusions. III. Lidocaine versus picrotoxin. Brain Res. Rev. 4: 129-136.

Foster, T. C., R. E. Hampson, M. O. West, and S. A. Deadwyler (1988) Control of sensory activation of granule cells in the fascia dentata by extrinsic afferents: Septal and entorhinal inputs. J. Neurosci. 8: 38693878.

Fox, S. E., and J. B. Ranck, Jr. (1975) Localization and anatomical identification of theta and complex spike cells in dorsal hippocampal formation of rats. Exp. Neurol. 49: 299-313.

Fox, S. E., and J. B. Ranck, Jr. (1981) Electrophysiological characteristics of hippocampal complex-spike and theta cells. Exp. Brain Res. 41: 399-410.

Fox, S. E., S. Wolfson, and J. B. Ranck, Jr. (1986) Hippocampal theta 
rhythm and the firing of neurons in waking and anesthetized rats. Exp. Brain Res. 62: 495-508.

Freund, T. F., and M. Antal (1988) GABA-containing neurons in the septum control inhibitory interneurons in the hippocampus. Nature 336: 170-173.

Frotscher, M., and C. Leranth (1985) Cholinergic innervation of the rat hippocampus as revealed by choline acetyltransferase immunocytochemistry: A combined light and electron microscopic study. J. Comp. Neurol. 239: 237-246.

Green, J. D., and A. Arduini (1954) Hippocampal electrical activity in arousal. J. Neurophysiol. 17: 533-557.

Haglund, L., L. W. Swanson, and C. Kohler (1984) The projections of the supramammillary nucleus to the hippocampal formation: An immunohistochemical and anterograde transport study with the lectin PHA-L in the rat. J. Comp. Neurol. 229: 171-185.

Hjorth-Simonsen, A. (1973) Some intrinsic connections of the hippocampus in the rat: An experimental analysis. J. Comp. Neurol. 147: 145-162.

Ishizuka, N., J. Weber, and D. G. Amaral (1989) Organization of the intrahippocampal projections originating from CA3 pyramidal cells in the rat. J. Comp. Neurol. (in press).

Jones, B. E., and R. T. Moore (1977) Ascending projections of the locus coeruleus in the rat. II. Autoradiographic study. Brain Res. 127: $23-54$.

Kohler, C. (1986) Intrinsic connections of the retrohippocampal region in the rat brain. II. The medial entorhinal area. J. Comp. Neurol. 246: $149-169$.

Kohler, C., V. Chan-Palay, and J.-Y. Wu (1984) Septal neurons containing glutamic acid decarboxylase immunoreactivity project to the hippocampal region in the rat brain. Anat. Embryol. 169: 41-44.

Malpeli, J. G., and P. H. Schiller (1979) A method of reversible inactivation of small regions of brain tissue. J. Neurosci. Methods 1 : 143-151.

Marr, D. A. (1969) A theory of cerebellar cortex. J. Physiol. (Lond.) 202: $437-470$.

Marr, D. A. (1971) Simple memory: A theory for archicortex. Phil. Trans. R. Soc. Ser. B. 262: 23-81.

McNaughton, B. L., and R. G. M. Morris (1987) Hippocampal synaptic enhancement and information storage within a distributed memory system. Trends Neurosci. 10: 408-415.

McNaughton, B. L., and L. Nadel (1989) Hebb-Marr networks and the neurobiological representation of action in space. In Neuroscience and Connectionist Theory, M. A. Gluck and D. E. Rummelhart, eds. Erlbaum, Hillsdale, NJ.

McNaughton, B. L., C. A. Barnes, and J. O'Keefe (1983a) The contributions of position, direction and velocity to single unit activity in the hippocampus of freely-moving rats. Exp. Brain Res. 52: 41-49.

McNaughton, B. L., J. O'Keefe, and C. A. Barnes (1983b) The stereotrode: A new technique for simultaneous isolation of several single units in the central nervous system from multiple unit records. $J$. Neurosci. Methods 8: 391-397.

Mesulam, M.-M., E. J. Mufson, B. H. Wainer, and A. I. Levey (1983) Central cholinergic pathways in the rat: An overview based on an alternative nomenclature (Ch1-Ch6). Neuroscience 10: 1185-1201.

Miller, S. W., and P. M. Groves (1977) Sensory evoked neuronal activity in the hippocampus before and after lesions of the medial septal nuclei. Physiol. Behav. 18: 141-146.

Miller, V. M., and P. J. Best (1980) Spatial correlates of hippocampal unit activity are altered by lesions of the fornix and entorhinal cortex. Brain Res. 194: 311-323.

Mizumori, S. J. Y., B. L. McNaughton, C. A. Barnes, and K. Fox (1987) Reversible inactivation of hippocampal afferents selectively reduces the spontaneous discharge rate of dentate units. Soc. Neurosci. Abstr. 13: 1102 .

Mizumori, S. J. Y., B. L. McNaughton, and C. A. Barnes (1989a) A comparison of supramammillary and medial septal influences on hippocampal field potentials and single unit activity. J. Neurophysiol. 61: $15-31$.

Mizumori, S. J. Y., C. A. Barnes, and B. L. McNaughton (1989b) Reversible inactivation of the medial septum: Selective effects on the spontaneous unit activity of different hippocampal cell types. Brain Res. (in press).

Molino, A., and D. McIntyre (1972) Another inexpensive headplug for electrical recording and/or stimulation of rats. Physiol. Behav. 9: 273-275.
Muller, R. U., J. L. Kubie, and J. B. Ranck, Jr. (1987) Spatial firing pattern of hippocampal complex-spike cells in a fixed environment. J. Neurosci. 7: 1935-1950.

O'Keefe, J. (1976) Place units in the hippocampus of the freely-moving rat. Exp. Neurol. 51: 78-109.

O'Keefe, J., and J. Dostrovsky (1971) The hippocampus as a spatial map. Preliminary evidence from unit activity in the freely-moving rat. Brain Res. 34: 171-175.

Olton, D. S., and R. J. Samuelson (1976) Remembrance of places passed: Spatial memory in rats. J. Exp. Psychol.: Anim. Behav. Proc. 2: $97-116$.

Olton, D. S., M. Branch, and P. J. Best (1978a) Spatial correlates of hippocampal unit activity. Exp. Neurol. 58: 387-409.

Olton, D. S., J. A. Walker, and F. H. Gage (1978b) Hippocampal connections and spatial discrimination. Brain Res. 139: 295-308.

Paxinos, G., and C. Watson (1982) The Rat Brain in Stereotaxic Coordinates, Academic, Sydney.

Perkel, D. H., G. L. Gerstein, and G. P. Moore (1967) Neuronal spike trains and stochastic point processes. I. The single spike train. Biophys. J. $7: 391-418$.

Proudfit, H. K. (1980) Reversible inactivation of raphe magnus neurons: Effects on nociceptive threshold and morphine-induced analgesia. Brain Res. 201: 459-464.

Ranck, J. B., Jr. (1973) Studies on single neurons in dorsal hippocampal formation and septum in unrestrained rats. Part 1. Behavioral correlates and firing repertoires. Exp. Neurol. 41: 461-555.

Rawlins, J. N. P., J. Feldon, and J. A. Gray (1979) Septo-hippocampal connections and the hippocampal theta rhythm. Exp. Brain Res. 37: 49-63.

Rigdon, G. C., and J. H. Pirch (1984) Microinjection of procaine or GABA into the nucleus basalis magnocellularis affects cue-elicited unit responses in the rat frontal cortex. Exp. Neurol. 85: 283-296.

Rose, G. (1983) Physiological and behavioral characteristics of dentate granule cells. In Neurobiology of the Hippocampus, W. Seifert, ed., pp. 449-472, Academic, New York.

Rose, A. M., T. Hattori, and H. C. Fibiger (1976) Analysis of the septo-hippocampal pathway by light and electron microscopic autoradiography. Brain Res. 108: 170-174.

Sandkuhler, J., B. Maisch, and M. Zimmermann (1987) The use of local anesthetic microinjections to identify central pathways: A quantitative evaluation of the time course and extent of the neuronal block. Exp. Brain Res. 68: 168-178.

Saper, C. B., L. W. Swanson, and W. M. Cowan (1979) An autoradiographic study of the efferent connections of the lateral hypothalamic area in the rat. J. Comp. Neurol. 183: 689-706.

Satoh, K., and H. C. Fibiger (1986) Cholinergic neurons of the laterodorsal tegmental nucleus: Efferent and afferent connections. J. Comp. Neurol. 253: 277-302.

Schiller, P. H., J. G. Malpeli, and S. J. Shein (1979) Composition of geniculostriate input to superior colliculus of the rhesus monkey. J. Neurophysiol. 42: 1124-1133.

Smith, D. C., R. A. Jensen, and T. M. Reeves (1983) Disruption of short- and long-term memory following reversible inactivation of the hippocampus. Soc. Neurosci. Abstr. 9: 332.

Sofroniew, M. V. (1985a) Vasopressin- and neurophysin-immunoreactive neurons in the septal region, medial amygdala and locus coerulcus in colchicinc-trcated rats. Neuroscience 15: 347-358.

Sofroniew, M. V. (1985b) Vasopressin, oxytocin and their related neurophysin. In Handbook of Chemical Neuroanatomy, Vol. 4: GABA and Neuropeptides in the CNS, Part I, A. Bjorklund and T. Hokfelt, eds., Elsevier, Amsterdam.

Steward, O. (1976) Topographic organization of the projections from the entorhinal area to the hippocampal formation of the rat. J. Comp. Neurol. 167: 285-314.

Steward, O., and S. A. Scoville (1976) Cells of origin of entorhinal cortical afferents to the hippocampus and fascia dentata of the rat. J. Comp. Neurol. 169: 347-370.

Swanson, L. W. (1976) An autoradiographic study of the efferent connections of the preoptic region in the rat. J. Comp. Neurol. 167: 227256.

Swanson, L. W., and W. M. Cowan (1979) The connections of the septal region in the rat. J. Comp. Neurol. 186: 621-656.

Swanson, L. W., and C. Kohler (1986) Anatomical evidence for direct projections from the entorhinal area to the entire cortical mantle in the rat. J. Neurosci. 6: 3010-3023. 
Swanson, L. W., J. M. Wyss, and W. M. Cowan (1978) An autoradiographic study of the organization of intrahippocampal association pathways in the rat. J. Comp. Neurol. 181: 681-716.

Thompson, L. T., and P. J. Best (1988) Hippocampal place cell to silent cell ratios in freely-behaving rats. Soc. Neurosci. Abstr. 14:126.

Vanderwolf, C. H. (1969) Hippocampal electrical activity and voluntary movement in the rat. Electroencephalogr. Clin. Neurophysiol. 26: 407-418.

Vincent, S. R., and E. G. McGeer (1981) A substance P projection to the hippocampus. Brain Res. 215: 349-351.

Vinogradova, O. S., and E. S. Brazhnik (1978) Neuronal aspects of the septohippocampal relations. In Functions of the Septo-Hippocampal System, Ciba Found. Symp., pp. 145-177, Elsevier, Amsterdam.

Winson, J. (1974) Patterns of hippocampal theta rhythm in the freely moving rat. Electroencephalogr. Clin. Neurophysiol. 36: 291-301.

Winson, J. (1978) Loss of hippocampal theta rhythm results in spatial memory deficit in the rat. Science 201: 160-163.

Witter, M. P., A. W. Griffioen, B. Jorritsma-Byham, and J. L. M. Krijnen (1988) Entorhinal projections to the hippocampal CAl region in the rat: An underestimated pathway. Neurosci. Lett. 85: 193-198. 